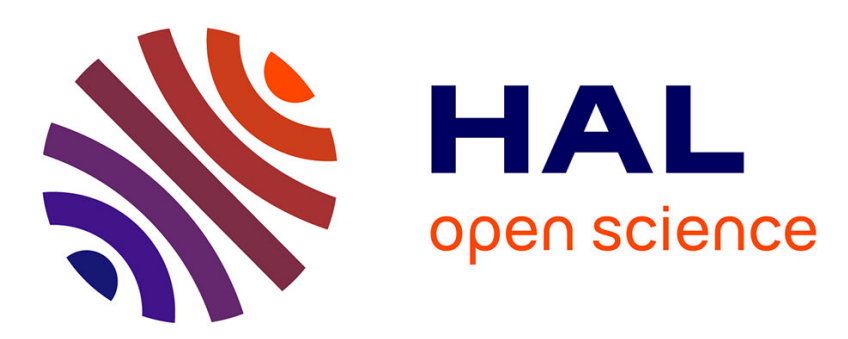

\title{
Fresh layers of RNA-mediated regulation in Gram-positive bacteria
}

Philippe Bouloc, Francis Repoila

\section{To cite this version:}

Philippe Bouloc, Francis Repoila. Fresh layers of RNA-mediated regulation in Gram-positive bacteria. Current Opinion in Microbiology, 2016, 30, pp.30 - 35. 10.1016/j.mib.2015.12.008 . hal-01412635

\section{HAL Id: hal-01412635 \\ https://hal.science/hal-01412635}

Submitted on 8 Dec 2016

HAL is a multi-disciplinary open access archive for the deposit and dissemination of scientific research documents, whether they are published or not. The documents may come from teaching and research institutions in France or abroad, or from public or private research centers.
L'archive ouverte pluridisciplinaire HAL, est destinée au dépôt et à la diffusion de documents scientifiques de niveau recherche, publiés ou non, émanant des établissements d'enseignement et de recherche français ou étrangers, des laboratoires publics ou privés. 


\section{Fresh layers of RNA-mediated regulation in Gram-positive bacteria Philippe Bouloc ${ }^{1}$ and Francis Repoila ${ }^{2}$}

Bacterial regulatory RNAs have been defined as diverse classes of cis and trans elements that may intervene at each step of gene expression, from RNA and protein synthesis to degradation. Here, we report on a few examples from Grampositive bacteria that extend the definition of regulatory RNAs to include $5^{\prime}$ and $3^{\prime}$ UTRs that also act as cis and trans regulators. New examples unveil the existence of cis and trans acting regulatory RNAs on a single molecule. Also, we highlight data showing that a key RNA chaperone in Enterobacteriaceae, $\mathrm{Hfq}$, does not fulfill the same role in Gram-positive Firmicutes.

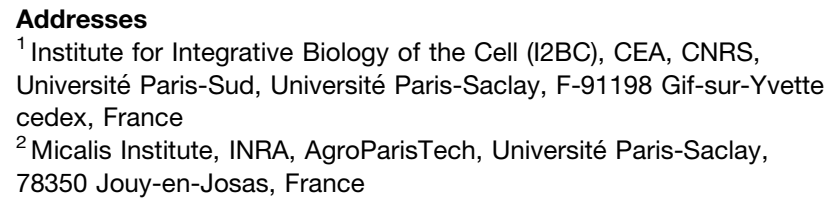

${ }^{2}$ Micalis Institute, INRA, AgroParisTech, Université Paris-Saclay, 78350 Jouy-en-Josas, France

Corresponding authors: Bouloc, Philippe (philippe.bouloc@u-psud.fr) and Repoila, Francis (francis.repoila@jouy.inra.fr)

\section{Introduction}

Bacterial survival results from the capacity of the cell to coordinate the expression of genes in response to changing environmental conditions, thus allowing it to adapt and gain novel niches. Besides many proteins, RNAmediated controls are crucial actors modulating gene expression in bacteria [1]. RNA-mediated regulation involves (i) a target element, either RNA or a protein, and (ii) an RNA-based element made up of a sequence intrinsic to the RNA target (cis-regulatory RNA) or a transcript encoded elsewhere in the genome (trans-regulatory RNA). Cis-regulatory RNAs are usually located at $5^{\prime}$ ends of messenger RNAs (mRNA). They fold in alternative structures that respond to physicochemical cues (e.g. temperature, pH) [2] or ligands (e.g., vitamins, nucleotides, ions, tRNA, or amino acids). These latter regulatory RNAs are usually called 'riboswitches' [3]. Trans-regulatory RNAs are encoded at loci that are distinct from their targets. They can bind to proteins, thereby affecting their activity, or pair to mRNAs, changing their translation efficiency, stability or termination.

Seminal publications in the last 20 years have defined these diverse classes of regulatory RNAs and unveiled their modes of action. However, recent studies in Firmicutes add 'fresh layers' to the diversity of RNA-mediated processes. This review highlights recent discoveries of diverse mechanisms whereby RNA mediates gene regulation in Gram positive bacteria.

\section{5'UTR, not only the beginning; 3'UTR, not only} the end; CDS, not only the coding sequence

A few regulatory RNAs containing an open reading frame, such as SgrS in enteric bacteria [4], SR1 in Bacillus subtilis [5], or RNAIII in Staphylococcus aureus [6], have been described. In these cases, the expressed proteins are small and tend to be seen as peculiarities of regulatory RNAs. More recently, additional mRNAs encoding transcriptional regulators were demonstrated to act as regulatory RNAs via their $5^{\prime}$ or $3^{\prime}$ untranslated regions (UTRs), suggesting that the duality 'protein-encoding and regulation' in RNA is more frequent than anticipated.

Bacterial $5^{\prime}$ untranslated regions (5'UTR) of mRNAs differ in length from a few to hundreds of nucleotides, and are central to numerous cis-regulatory functions. These regions may also sequester regulatory RNAs [710] or act as a trans-acting factor [11].

Streptococcus mutans is a Gram-positive oral commensal causative agent of dental cavities in humans, producing glucan-binding proteins (Gbp). One of them, GbpC, contributes to biofilm formation, cariogenesis, bacteremia, and infective endocarditis. Its transcription is stimulated by an unusual mechanism involving the irvA transcriptional repressor gene $\left[12^{\circ}\right]$. Surprisingly, the IrvA protein is not the regulatory element required for $g b p C$ expression; the process depends solely on an irvA mRNA/ gbpC mRNA interaction, and only the irvA mRNA 5'UTR is required. Interestingly, the $g b p C$ mRNA target region is not its $5^{\prime} \mathrm{U} T R$, but the coding sequence (Figure 1a). The $g b p C$ mRNA is susceptible to RNase J2-mediated degradation but its pairing with irvA mRNA promotes its stabilization and consequently its translation (Figure 1a). Expression of irvA is controlled by IrvR, a self-cleaving LexA-like regulator [13], and environmental stresses, including the sweetener xylitol, trigger $g b p C$ expression by affecting its activation regulatory cascade. 


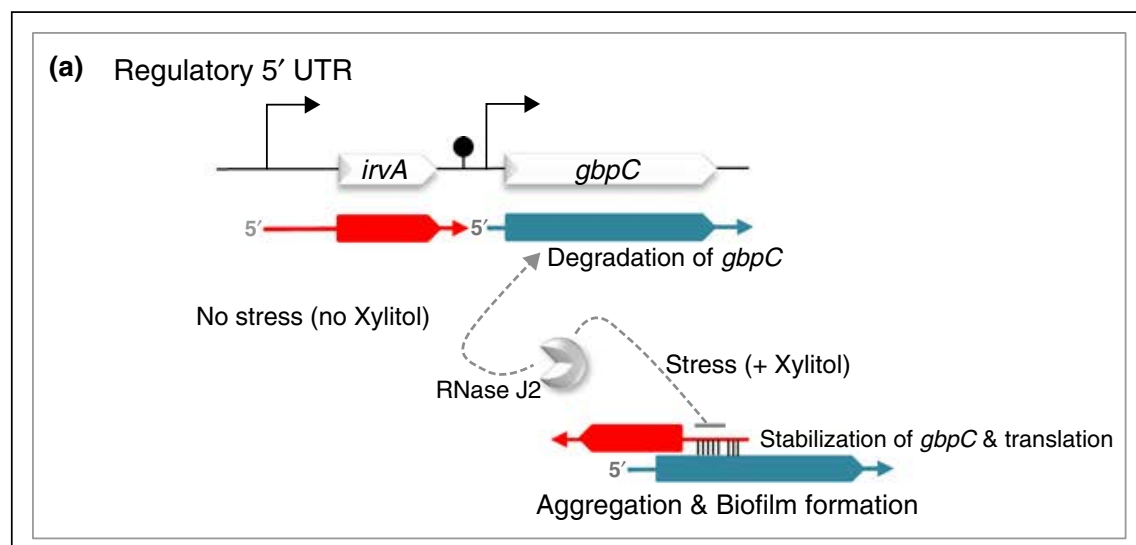

(b) Regulatory 3' UTR

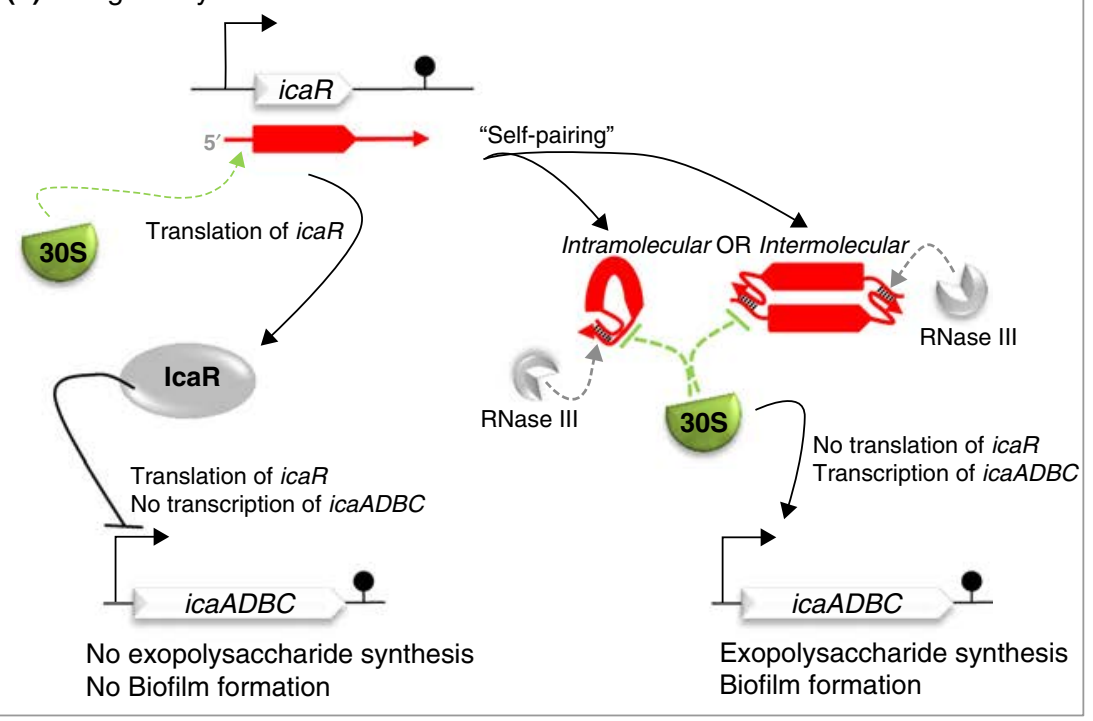

(c) RNA controls RNA to control RNA synthesis
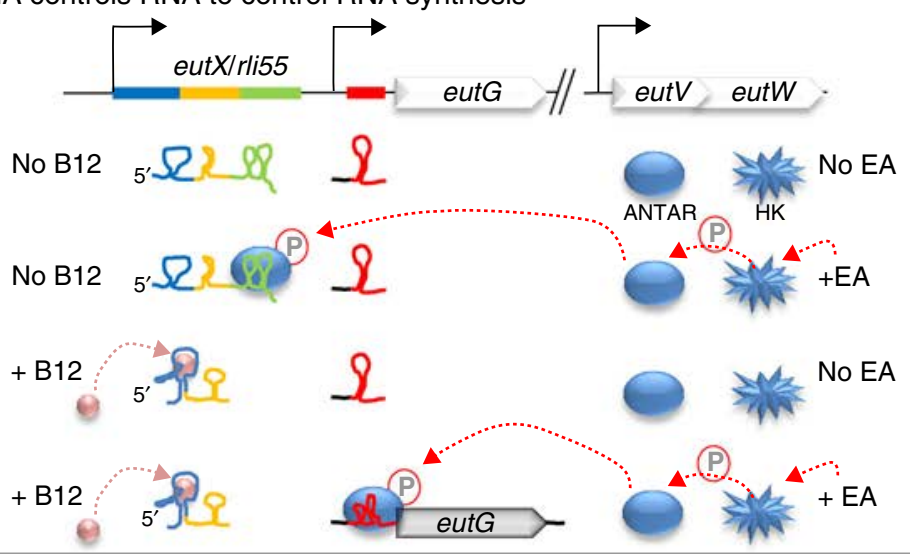

Current Opinion in Microbiology

(a) Regulatory $5^{\prime}$ UTR. In S. mutans, expression of glucan-binding protein $\mathrm{C}$ is enhanced by irvA mRNA. irvA mRNA pairs to the coding sequence of gbpC mRNA and stabilizes it by preventing RNase $\mathrm{J} 2$ degradation [12 ${ }^{\circ}$. (b) Regulatory $3^{\prime}$ UTR. icaR mRNA translation in S. aureus is autocontrolled. icaR encodes a transcriptional repressor of exopolysaccharide synthesis. Depending on environmental conditions, icaR mRNA is translated (left part of panel) or not (right part). Repression of icaR translation is due to pairing of the $3^{\prime} U T R$ to the $5^{\prime} U T R$ of the mRNA. The reaction can be intra- or inter-molecular. The formed RNA duplex is recognized and cleaved by RNase III [15]. (c) RNA controls RNA to control RNA synthesis. Utilization of ethanolamine (EA) as a source of carbon and nitrogen involves the eut operon (symbolized by the first ORF, eutG), 
Demonstration of the dual function of the irva gene highlights the possibility that many $5^{\prime} \mathrm{UTR}$ may contribute to regulation independently of their associated coding sequence.

The Hfq protein is a key RNA chaperone in Enterobacteriaceae involved in the vast majority of RNA duplexes formed between a trans-regulatory RNA and its mRNA target. The recent discovery of mRNA $3^{\prime}$ regions enriched by co-immunoprecipitation with $\mathrm{Hfq}$ in Salmonella and Escherichia coli suggested that these sequences were functionally active in an Hfq-dependent manner (reviewed in [14]). These $3^{\prime}$ RNA regions could originate (i) from internal promoters to mRNA genes (Type I) or (ii) from mRNA processing (Type II). In both cases, they are a source of regulatory RNAs that end at mRNA terminators [15]. The interactions between $3^{\prime}$ RNA ends and Hfq are documented in Enterobacteriaceae and suggest a regulatory role for these RNA sequences. However, it is not the case in Gram-positive bacteria where the function of $\mathrm{Hfq}$ remains elusive (see below). Nevertheless, tiling-arrays and RNAseq data revealed an unexpected high density of transcription, with $3^{\prime} \mathrm{UTR}$ s that are long and sometimes conserved [16-18,19 ${ }^{\circ}$ ]. $3^{\prime}$ UTRs may also participate in RNA-mediated control: about one-third of characterized staphylococcal mRNAs have long $3^{\prime}$ UTR (>100 nt), underscoring their potential importance. Recently, the function of one of these extensions was tackled [20 $0^{\circ \bullet}$. The icaR mRNA is about $1000 \mathrm{nt}$ long and encodes a translational regulator from the TetR family (IcaR), which down-regulates synthesis of a main biofilm exopolysaccharide. The icaR $390 \mathrm{nt}$ long $3^{\prime}$ UTR pairs with the icaR $5^{\prime}$ end over about $40 \mathrm{nt}$. This $3^{\prime} \mathrm{UTR}$ includes a C-rich region that interacts with the $i c a R$ Shine-Dalgarno (SD) sequence. Deletion of the $3^{\prime}$ UTR leads to increased levels of IcaR due to stabilization and improved translation of icaR mRNA. Interestingly, authors favor the hypothesis that the UTR acts in cis, bridging the $5^{\prime}$ and $3^{\prime}$ ends and leading to a circular mRNA structure with a stem-loop (Figure $1 \mathrm{~b}$ ). These results are reminiscent of the intermolecular interactions of the hok/ sok mRNA of plasmid R1 modulating toxin translation [21]. While $3^{\prime}$ UTR sequences controlling RNA stability and translation in eukaryotic mRNAs are widely acknowledged, icaR expression control by a $3^{\prime}-5^{\prime}$ intramolecular mRNA pairing is thus far an unconventional mode of regulation in bacteria.

\section{Long and overlapping RNAs}

Transcription of two opposite DNA strands generates RNAs that can associate by base pairing and contribute to antisense RNA (asRNA) regulation. In Listeria monocytogenes, the presence of unusually long $3^{\prime}$ or $5^{\prime}$ UTRs, extending over the opposite strands of adjacent genes, led to the concept of 'excludon', which defines the class of genomic loci encoding long asRNAs spanning divergent neighboring genes with related or mutually exclusive functions $[22,23]$. The mechanistics behind the excludon are not yet characterized. However, one actor in its regulation is likely the double-stranded RNA (dsRNA)-specific nuclease RNaseIII: a recent high-throughput study in E. coli using dsRNA-specific antibody (at least 40-mers) led to the identification of asRNAs associated with their cognate sense RNAs in an RNase III-dependent manner, supporting the existence of numerous functional complexes [24]. Observations in $S$. aureus also identify widespread antisense transcription and the role of RNase III in mediating degradation of overlapping transcripts $[18,25]$.

Transcription termination is an obvious means of controlling antisense organization. Interestingly, it can be modulated by its $5^{\prime}$ sequence either being a riboswitch or pairing to a trans-acting regulatory RNA. In both cases, they affect the activity of the transcription termination factor Rho $[7,8,26]$. Genome-wide alteration of termination may have a drastic impact; for instance, Rho is an essential protein in E. coli [27]. However, rho mutants in S. aureus and B. subtilis are viable. In B. subtilis, mRNA extensions can reach up to $12 \mathrm{~kb}$, and Rho appears as a general inhibitor of antisense transcription $\left[19^{\circ}\right]$. Yet in its absence, Firmicutes survive even with extensive inappropriate antisense transcripts, therefore questioning why this aberrant transcription is not deleterious and consequently what is the impact of pervasive transcription in this phylum.

\section{RNA controls RNA to control RNA synthesis}

A key element of RNA-based regulation is their transcription, which is often conditionally controlled $\left[19^{\circ}\right]$. Recently, a new level of complexity was observed in Gram-positive bacteria, with a riboswitch-controlled trans-acting RNA. Ethanolamine (EA) is an abundant molecule of the gastrointestinal environment produced by hydrolysis of phosphatidylethanolamine, a crucial component of cell membranes. EA is used as a nitrogen source by many bacteria, but is also utilized as a carbon source by enteropathogens to outcompete the resident microbiota [28]. Among them, Firmicutes Enterococcus faecalis and L. monocytogenes employ a sophisticated RNA-mediated regulation strategy, combining riboswitch-termination, sRNA-termination and antitermination dependent processes to coordinate EA catabolism

(Figure 1 Legend Continued) the two-component system eutVW and the sRNA-riboswitch eutX or rli55 (described in $E$. faecalis or $L$. monocytogenes, respectively; $\left[2^{\circ}, 30^{\circ}\right]$ ), and requires vitamin B12 (B12). In the presence of EA, the anti-terminator 'ANTAR' protein (i.e., containing an RNA binding domain; [32]), EutV, is activated by phosphorylation, and binds preferentially to an RNA-sequestering sequence present at the $3^{\prime}$ end of EutX/Rli55. Transcription of the eut operon is stopped by a transcriptional terminator upstream of eutG. When B12 is present, it binds to the riboswitch structure at the $5^{\prime}$ end of EutX/Rli55, and transcription stops upstream of the RNA binding sequence recognized by the activated EutV. The latter binds to the transcription terminator upstream of eutG, and transcription of the eut operon may then proceed. 
with nutrient availability $\left[29^{\bullet \bullet}, 30^{\bullet \bullet}\right]$. In these species, EA utilization requires expression of the eut operon, comprising over a dozen open reading frames (ORFs), and a sRNA encoding gene, eut $X$ in E. faecalis or rli55 in $L$. monocytogenes, which lies upstream of eut. Transcription of eut $X /$ rli55 is controlled by a B12-riboswitch aptamer [31]. Full expression of eut is achieved in the presence of EA and vitamin B12, an essential cofactor for enzymes encoded by the operon. In E. faecalis, EA in the environment is sensed by a two component system comprising a histidine kinase, EutW, and its cognate response regulator EutV that belongs to the ANTAR RNA-binding protein family. ANTAR regulatory proteins act as transcription antiterminators [32]. When EA is absent, eut transcription stops at a terminator preceding the first ORF of the operon (eut $G)$, and $\mathrm{EutV}$ is not phosphorylated and inactive; in this condition, eutX/rli55 produces a full length sRNA. In the presence of EA, EutV is phosphorylated and binds to EutX/Rli55. EutV is thereby inactive on eut expression as it is sequestered by the sRNA. When EA and B12 are both present, B12 binds to the aptamer of EutX/Rli55 and provokes formation of a transcription terminator upstream of the EutV binding sequence, generating a truncated sRNA that no longer sequesters the active response regulator. EutV then binds to the nascent eut operonic RNA and allows transcription of downstream ORFs (Figure 1c).

\section{The Hfq mystery in Gram-positive bacteria}

Hfq is a well-characterized RNA binding protein involved in post-transcriptional regulation (reviewed in [33]). In Enterobacteriaceae, Hfq stimulates base-pairing of transencoded RNAs with their RNA-partner molecules and consequently, its absence produces highly pleiotropic phenotypes.

However, within the Firmicutes phylum, Hfq is either not found (e.g. Lactobacillales) or when present, it seems to marginally affect adaptation and gene expression. The absence of Hfq in B. subtilis and S. aureus does not impact growth in nearly two thousand tested growth conditions [34,35], nor L. monocytogenes in standard laboratory growth conditions [36]. Nevertheless, in L. monocytogenes, Hfq does contribute to osmotic and ethanol stress adaptation [36]. Comparative transcriptome studies in these organisms with their respective $h f q$ derivatives reveal moderate or no transcriptional variations as compared to Enterobacteriaceae [17,34,37,38]. Although Hfqs of these Grampositive species bind to RNAs [37,39,40], their contribution in sRNA-mediated regulation remains enigmatic. So far, no sRNA-dependent regulation in $S$. aureus and $B$. subtilis was shown to require Hfq (e.g. in S. aureus [41-44] and in B. subtilis [45-49]). In B. subtilis $\mathrm{Hfq}$ is required for ahr $C$ mRNA translation, a target of SR1 sRNA; oddly, however, the stimulatory effect of Hfq is SR1-independent $[46,47]$. Within the class of Bacilli, the only documented sRNA/Hfq-dependent regulation concerns the $L$. monocytogenes sRNA LhrA, which directly down-regulates expression of at least three genes and is protected from degradation by $\mathrm{Hfq}[50,51]$. However, a transcriptome study indicated that in the tested conditions, the absence of Hfq did not impact the abundance of over 60 sRNAs (including LhrA) [17,52]. Consequently, as was seen in S. aureus and B. subtilis, sRNA stabilization by $\mathrm{Hfq}$ in Listeria is likely not a general trait. Complementation of either Salmonella or E. coli $\Delta h f q$ mutants has often been obtained by $h f q$ genes from other species (e.g. [53]); however Hfq from $B$ subtilis or $S$. aureus does not compensate the absence of Hfq in Salmonella [34,54]. These results indicate that the ability of those Hfq proteins to stimulate sRNA/mRNA regulation is either lost or restricted to specific pairs.

As genomes of Firmicutes have a low GC content, it was suggested that RNA pairing properties would be different in this phylum and consequently $\mathrm{Hfq}$ would not be required for sRNA-mediated regulation [55]. However, recent results show that $\mathrm{Hfq}$ plays an essential role in Clostridium difficile $\left[56^{\circ}\right]$ which is $29 \%$ GC. Depletion of Hfq drastically affects its growth and gene expression, and notably, alters the levels of sRNAs shown to bind Hfq $\left[56^{\circ}\right.$. Hfq from $C$. difficile restores phenotypes associated to the $\Delta h f q$ mutation in $E$. coli [53], further supporting its functional role in sRNA regulation.

Hfq forms a homo-hexameric donut-like structure. A conserved arginine rich sequence (RRER) on the outer rim of $\mathrm{Hfq}$ is required for E. coli $\mathrm{Hfq}$ chaperone function [57]. This motif is not conserved in $S$. aureus $\mathrm{Hfq}$, and the presence of just one arginine in B. subtilis and Listeria [57] may explain why Hfq is not associated with general sRNA regulations. In contrast, two arginines present in the Clostridium Hfq motif (RKER) may contribute to its activity.

The $h f q$ gene is present in most, if not all, natural isolates of $B$ subtilis, $S$ aureus and Listeria. It was recently shown that Hfq is involved in B. subtilis stationary phase survival and therefore provides a selective advantage for this soil bacterium, which encounters starvation periods [34,38]. Similarly, Hfq contributes to the long-term survival of L. monocytogenes under amino-acid-limiting conditions, which could explain its contribution to pathogenicity [36]. Possibly, the observed $h f q$ virulence-associated phenotype in $S$. aureus [37] could be related to adaptation to stationary phase. In contrast to the generalized activity of Hfq proteins in Enterobacteriaceae, the orthologs present in the Firmicutes appear to act on a restricted set of substrates, indicating a more specialized role.

\section{Concluding remarks}

Past discoveries on posttranscriptional regulation initially emerged from studies in E. coli and Salmonella. The new results from Gram-positive bacteria, some of which are highlighted here, bring to light a wide diversity of 
mechanisms that regulate bacterial physiology. Different mechanisms may have been selected to cope with specific sets of enzymes acting on RNA metabolism (e.g. RNases $[58,59]$ ), alternate composition (e.g. to accommodate low $\mathrm{G}+\mathrm{C}$ genome composition) or other evolutionary constraints. Analysis of the distribution of short and long RNA fractions in several Firmicutes revealed the existence of a generalized antisense transcription with processing patterns that differ from those in Gram-negative bacteria [18]. Different phyla were shown to have distinct regulatory features, for example, with respect to sRNA Hfqdependency, Rho essentiality, and RNase components. We expect that novel alternative regulatory solutions established in Gram-positive bacteria remain to be found.

\section{Acknowledgements}

Work in the authors' laboratories was supported by a grant from the Agence Nationale pour la Recherche (ANR-12-BSV6-0008 - ReadRNA) and French governmental institutions CNRS and INRA. We thank Sandy Gruss and

Grim Bergen for critical reading of the manuscript, helpful discussions and refreshing support.

\section{References and recommended reading}

Papers of particular interest, published within the period of review, have been highlighted as:

- of special interest

$\bullet$ of outstanding interest

1. Wagner EG, Romby P: Small RNAs in bacteria and archaea: who they are, what they do, and how they do it. Adv Genet 2015, 90:133-208.

2. Johansson J, Mandin P, Renzoni A, Chiaruttini C, Springer M, Cossart P: An RNA thermosensor controls expression of virulence genes in Listeria monocytogenes. Cell 2002, 110:551-561.

3. Roth A, Breaker RR: The structural and functional diversity of metabolite-binding riboswitches. Annu Rev Biochem 2009, 78:305-334.

4. Wadler CS, Vanderpool CK: A dual function for a bacterial small RNA: SgrS performs base pairing-dependent regulation and encodes a functional polypeptide. Proc Natl Acad Sci U S A 2007, 104:20454-20459.

5. Gimpel M, Heidrich N, Mader U, Krugel H, Brantl S: A dualfunction sRNA from $B$. subtilis: SR1 acts as a peptide encoding mRNA on the gapA operon. Mol Microbiol 2010, 76:990-1009.

6. Novick RP, Ross HF, Projan SJ, Kornblum J, Kreiswirth B, Moghazeh S: Synthesis of staphylococcal virulence factors is controlled by a regulatory RNA molecule. EMBO J 1993 12:3967-3975.

7. Figueroa-Bossi N, Valentini M, Malleret L, Fiorini F, Bossi L: Caught at its own game: regulatory small RNA inactivated by an inducible transcript mimicking its target. Genes Dev 2009, 23:2004-2015

8. Rasmussen AA, Johansen J, Nielsen JS, Overgaard M, Kallipolitis B, Valentin-Hansen P: A conserved small RNA promotes silencing of the outer membrane protein YbfM. Mol Microbiol 2009, 72:566-577.

9. Lalaouna D, Carrier MC, Semsey S, Brouard JS, Wang J, Wade JT, Masse E: A $3^{\prime}$ external transcribed spacer in a tRNA transcript acts as a sponge for small RNAs to prevent transcriptional noise. Mol Cell 2015, 58:393-405.

10. Miyakoshi M, Chao Y, Vogel J: Cross talk between ABC transporter mRNAs via a target mRNA-derived sponge of the GcvB small RNA. EMBO J 2015, 34:1478-1492.
11. Loh E, Dussurget O, Gripenland J, Vaitkevicius K, Tiensuu T Mandin P, Repoila F, Buchrieser C, Cossart P, Johansson J: A trans-acting riboswitch controls expression of the virulence regulator PrfA in Listeria monocytogenes. Cell 2009, 139:770-779.

12. Liu N, Niu G, Xie Z, Chen Z, Itzek A, Kreth J, Gillaspy A, Zeng L,

- Burne R, Qi F et al.: The Streptococcus mutans irvA gene encodes a trans-acting riboregulatory mRNA. Mol Cell 2015, $57: 179-190$.

This study demonstrates the trans-acting activity of a $5^{\prime}$ UTR and suggests that any protein-encoding mRNAs may act as trans-acting regulator.

13. Niu G, Okinaga T, Zhu L, Banas J, Qi F, Merritt J: Characterization of irvR, a novel regulator of the irvA-dependent pathway required for genetic competence and dextran-dependent aggregation in Streptococcus mutans. J Bacteriol 2008, 190:7268-7274.

14. Miyakoshi M, Chao Y, Vogel J: Regulatory small RNAs from the $3^{\prime}$ regions of bacterial mRNAs. Curr Opin Microbiol 2015, 24:132-139.

15. Chao $Y$, Papenfort $K$, Reinhardt $R$, Sharma $C M$, Vogel J: An atlas of Hfq-bound transcripts reveals 3' UTRs as a genomic reservoir of regulatory small RNAs. EMBO J 2012, 31:4005-4019.

16. Rasmussen $\mathrm{S}$, Nielsen HB, Jarmer $\mathrm{H}$ : The transcriptionally active regions in the genome of Bacillus subtilis. Mol Microbiol 2009, 73:1043-1057.

17. Toledo-Arana A, Dussurget $O$, Nikitas $G$, Sesto N, Guet-Revillet $H$ Balestrino D, Loh E, Gripenland J, Tiensuu T, Vaitkevicius K et al. The Listeria transcriptional landscape from saprophytism to virulence. Nature 2009, 459:950-956.

18. Lasa I, Toledo-Arana A, Dobin A Villanueva M, de los Mozos IR Vergara-Irigaray M, Segura V, Fagegaltier D, Penades JR, Valle $J$ et al.: Genome-wide antisense transcription drives mRNA processing in bacteria. Proc Natl Acad Sci U S A 2011 , 108.20172-20177.

19. Nicolas P, Mader U, Dervyn E, Rochat T, Leduc A, Pigeonneau N,

- Bidnenko E, Marchadier E, Hoebeke M, Aymerich S et al. Condition-dependent transcriptome reveals high-level regulatory architecture in Bacillus subtilis. Science 2012, 335:1103-1106.

Transcriptomic study from nearly 3000 promotors in 104 growth conditions reveals the transcription complexity of a Gram positive bacterium.

20. Ruiz de los Mozos I, Vergara-Irigaray M, Segura V, Villanueva M,

- Bitarte N, Saramago M, Domingues S, Arraiano CM, Fechter P. Romby P et al.: Base pairing interaction between $5^{\prime}$ - and $3^{\prime}$ UTRs controls, icaR., mRNA., translation in Staphylococcus aureus. PLoS Genet 2013, 9:e1004001.

Example of a post-transcriptional regulation via the interaction of a $5^{\prime}$ and $3^{\prime}$ UTRs of the same mRNA. It suggests that long $3^{\prime} U T R s$ often present in $S$. aureus may have major regulatory roles.

21. Gerdes K, Wagner EG: RNA antitoxins. Curr Opin Microbio/ 2007, 10:117-124.

22. Sesto N, Wurtzel O, Archambaud C, Sorek R, Cossart P: The excludon: a new concept in bacterial antisense RNA-mediated gene regulation. Nat Rev Microbiol 2013, 11:75-82.

23. Wurtzel O, Sesto N, Mellin JR, Karunker I, Edelheit S, Becavin C Archambaud C, Cossart P, Sorek R: Comparative transcriptomics of pathogenic and non-pathogenic Listeria species. Mol Syst Biol 2012, 8:583.

24. Lybecker M, Zimmermann B, Bilusic I, Tukhtubaeva N Schroeder R: The double-stranded transcriptome of Escherichia coli. Proc Natl Acad Sci U S A 2014, 111:3134-3139.

25. Lioliou E, Sharma CM, Caldelari I, Helfer AC, Fechter P, Vandenesch F, Vogel J, Romby P: Global regulatory functions of the Staphylococcus aureus endoribonuclease III in gene expression. PLoS Genet 2012, 8:e1002782.

26. Hollands K, Proshkin S, Sklyarova S, Epshtein V, Mironov A, Nudler E, Groisman EA: Riboswitch control of Rho-dependent transcription termination. Proc Natl Acad Sci U S A 2012, 109:5376-5381. 
27. Bubunenko M, Baker T, Court DL: Essentiality of ribosomal and transcription antitermination proteins analyzed by systematic gene replacement in Escherichia coli. J Bacteriol 2007, 189:2844-2853.

28. Staib L, Fuchs TM: From food to cell: nutrient exploitation strategies of enteropathogens. Microbiology 2014, 160: 1020-1039.

29. DebRoy S, Gebbie M, Ramesh A, Goodson JR, Cruz MR, van

- Hoof A, Winkler WC, Garsin DA: Riboswitches. A riboswitchcontaining sRNA controls gene expression by sequestration of a response regulator. Science 2014, 345:937-940.

See annotation to Ref. [30॰0].

30. Mellin JR, Koutero M, Dar D, Nahori MA, Sorek R, Cossart P:

- Riboswitches. Sequestration of a two-component response regulator by a riboswitch-regulated noncoding RNA. Science 2014, 345:940-943.

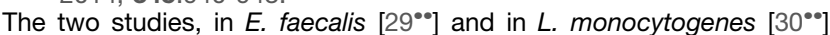
demonstrate the interplay of a riboswitch, a small RNA and an antiterminator regulator to control the expression of eut operon involved in ethanolamine metabolism. This complex RNA-based regulation allows multiple metabolite-dependent controls.

31. Mellin JR, Cossart $P$ : Unexpected versatility in bacterial riboswitches. Trends Genet 2015, 31:150-156.

32. Stewart V, van Tilbeurgh H: Found: the elusive ANTAR transcription antiterminator. PLoS Genet 2012, 8:e1002773.

33. Vogel J, Luisi BF: Hfq and its constellation of RNA. Nat Rev Microbiol 2011, 9:578-589.

34. Rochat T, Delumeau O, Figueroa-Bossi N, Noirot P, Bossi L, Dervyn E, Bouloc P: Tracking the elusive function of Bacillus subtilis Hfq. PLoS One 2015, 10:e0124977.

35. Bohn C, Rigoulay C, Bouloc P: No detectable effect of RNAbinding protein $\mathrm{Hfq}$ absence in Staphylococcus aureus. BMC Microbiol 2007, 7:10.

36. Christiansen JK, Larsen $\mathrm{MH}$, Ingmer H, Sogaard-Andersen L, Kallipolitis BH: The RNA-binding protein Hfq of Listeria monocytogenes: role in stress tolerance and virulence. J Bacteriol 2004, 186:3355-3362.

37. Liu Y, Wu N, Dong J, Gao Y, Zhang X, Mu C, Shao N, Yang G: Hfq is a global regulator that controls the pathogenicity of Staphylococcus aureus. PLoS One 2010:5.

38. Hammerle H, Amman F, Vecerek B, Stulke J, Hofacker I, Blasi U: Impact of Hfq on the Bacillus subtilis transcriptome. PLoS One 2014, 9:e98661.

39. Dambach M, Irnov I, Winkler WC: Association of RNAs with Bacillus subtilis Hfq. PLoS One 2013, 8:e55156.

40. Christiansen JK, Nielsen JS, Ebersbach T, Valentin-Hansen P, Sogaard-Andersen L, Kallipolitis BH: Identification of small Hfqbinding RNAs in Listeria monocytogenes. RNA 2006 , 12:1383-1396.

41. Geisinger E, Adhikari RP, Jin R, Ross HF, Novick RP: Inhibition of rot translation by RNAIll, a key feature of agr function. Mol Microbiol 2006, 61:1038-1048.

42. Boisset $\mathrm{S}$, Geissmann T, Huntzinger E, Fechter $\mathrm{P}$, Bendridi N, Possedko M, Chevalier C, Helfer AC, Benito Y, Jacquier A et al.: Staphylococcus aureus RNAIII coordinately represses the synthesis of virulence factors and the transcription regulator Rot by an antisense mechanism. Genes Dev 2007 21:1353-1366

43. Geissmann T, Chevalier C, Cros MJ, Boisset S, Fechter P Noirot C, Schrenzel J, Francois P, Vandenesch F, Gaspin C et al.: A search for small noncoding RNAs in Staphylococcus aureus reveals a conserved sequence motif for regulation. Nucleic Acids Res 2009, 37:7239-7257.

44. Chabelskaya S, Gaillot O, Felden B: A Staphylococcus aureus small RNA is required for bacterial virulence and regulates the expression of an immune-evasion molecule. PLOS Pathog 2010, 6:e1000927.

45. Gaballa A, Antelmann H, Aguilar C, Khakh SK, Song KB, Smaldone GT, Helmann JD: The Bacillus subtilis iron-sparing response is mediated by a Fur-regulated small RNA and three small, basic proteins. Proc Natl Acad Sci U S A 2008, 105:11927-11932.

46. Heidrich N, Chinali A, Gerth U, Brantl S: The small untranslated RNA SR1 from the Bacillus subtilis genome is involved in the regulation of arginine catabolism. Mol Microbiol 2006, 62:520-536.

47. Heidrich N, Moll I, Brantl S: In vitro analysis of the interaction between the small RNA SR1 and its primary target ahrC mRNA. Nucleic Acids Res 2007, 35:4331-4346.

48. Silvaggi JM, Perkins JB, Losick R: Small untranslated RNA antitoxin in Bacillus subtilis. J Bacteriol 2005, 187:6641-6650.

49. Durand S, Braun F, Lioliou E, Romilly C, Helfer AC, Kuhn L, Quittot N, Nicolas P, Romby P, Condon C: A: A nitric oxide regulated small RNA controls expression of genes involved in redox homeostasis in Bacillus subtilis. PLoS Genet 2015, 11:e1004957.

50. Nielsen JS, Larsen MH, Lillebaek EM, Bergholz TM, Christiansen $\mathrm{MH}$, Boor KJ, Wiedmann M, Kallipolitis BH: A small RNA controls expression of the chitinase ChiA in Listeria monocytogenes. PLoS One 2011, 6:e19019.

51. Nielsen JS, Lei LK, Ebersbach T, Olsen AS, Klitgaard JK, ValentinHansen $\mathrm{P}$, Kallipolitis $\mathrm{BH}$ : Defining a role for Hfq in Grampositive bacteria: evidence for Hfq-dependent antisense regulation in Listeria monocytogenes. Nucleic Acids Res 2010 38:907-919.

52. Mandin P, Repoila F, Vergassola M, Geissmann T, Cossart P Identification of new noncoding RNAs in Listeria monocytogenes and prediction of mRNA targets. Nucleic Acids Res 2007, 35:962-974.

53. Caillet J, Gracia C, Fontaine F, Hajnsdorf E: Clostridium difficile Hfq can replace Escherichia coli Hfq for most of its function RNA 2014, 20:1567-1578.

54. Rochat T, Bouloc P, Yang Q, Bossi L, Figueroa-Bossi N: Lack of interchangeability of Hfq-like proteins. Biochimie 2012, 94:1554-1559.

55. Jousselin A, Metzinger L, Felden B: On the facultative requirement of the bacterial RNA chaperone Hfq. Trends Microbiol 2009, 17:399-405.

56. Boudry P, Gracia C, Monot M, Caillet J, Saujet L, Hajnsdorf E,

- Dupuy B, Martin-Verstraete I, Soutourina O: Pleiotropic role of the RNA chaperone protein Hfq in the human pathogen Clostridium difficile. J Bacteriol 2014, 196:3234-3248.

First example of a pleotric role of $\mathrm{Hfq}$ in a Gram positive bacterium.

57. Panja S, Schu DJ, Woodson SA: Conserved arginines on the rim of Hfq catalyze base pair formation and exchange. Nucleic Acids Res 2013, 41:7536-7546.

58. Bonnin RA, Bouloc P: RNA degradation in Staphylococcus aureus: diversity of ribonucleases and their impact. Int $J$ Genom 2015, 2015:395753.

59. Hui MP, Foley PL, Belasco JG: Messenger RNA degradation in bacterial cells. Annu Rev Genet 2014, 48:537-559. 